\title{
Clinicopathological significance of fascin and CD44v6 expression in endometrioid carcinoma
}

\author{
Banu Dogan Gun*, Burak Bahadir, Sibel Bektas, Figen Barut, Gamze Yurdakan, Nilufer Onak Kandemir \\ and Sukru Oguz Ozdamar
}

\begin{abstract}
Background: Fascin and CD44v6 may have significant roles as biomarkers in tumour progression and metastasis. In endometrioid carcinomas, the fascin expression profile is less defined, and the significance of CD44v6 is uncertain. We aimed to investigate the expressions of both fascin and CD44v6 in endometrioid carcinomas and to evaluate their inter-relation with clinicopathological parameters.

Methods: Fascin and CD44v6 expressions were evaluated, individually and in combination, in a series of 47 endometrioid carcinomas and 10 proliferative endometrium samples. The staining extent and intensity of both markers in tumour cells were scored semiquantitatively. The relationship between immunoexpressions and clinicopathological variables was assessed.

Results: The expression rates of fascin and CD44v6 in endometrioid carcinoma were $72.34 \%$ and $46.80 \%$, respectively. Although these expression rates were higher than those in proliferative endometrial samples, fascin expression showed a statistically significant difference from the normal group $(p=0.02)$, but CD44v6 did not differ $(p=0.54)$. Fascin expression was significantly correlated with tumour grade $(p=0.003)$ and neural invasion $(p=0.036)$ in a univariate analysis. In contrast, no significant correlation was found between CD44v6 and any of the clinicopathological parameters.
\end{abstract}

Conclusions: Our findings suggest that fascin might be an independent prognostic indicator in the different steps of extracellular matrix invasion. On the other hand, CD44v6 was not a predictive factor in endometrioid cancer.

Virtual Slides: The virtual slide(s) for this article can be found here: http://www.diagnosticpathology.diagnomx.eu/ vs/8511594927206899.

Keywords: Fascin, CD44v6, Endometrioid carcinoma, Immunohistochemistry

\section{Background}

Endometrial carcinoma is the most common invasive neoplasm in the female genital tract. Based on clinicopathological and molecular genetic features, it can be divided into two major groups referred to as type I and type II. The endometrioid subtype, which is the prototype of type I carcinoma, is associated with unopposed estrogenic stimulation, as well as endometrial hyperplasia. Prognosis is dependent on some wellaccepted clinical and pathological parameters, including the histological type and grade of the tumour, the depth

\footnotetext{
* Correspondence: banudogangun@yahoo.com

Department of Pathology, Faculty of Medicine, Bulent Ecevit University, 67100 Kozlu, Zonguldak, Turkey
}

\section{() Biomed Central}

and pattern of myometrial invasion, the degree of disease extension beyond the uterine corpus, adnexal involvement, and pelvic and para-aortic lymph node metastasis [1]. Although several common molecular alterations have been identified in the pathogenesis of endometrial cancer [2-4], additional molecular factors need to be defined to predict the specific behaviour of the tumour.

The interaction between epithelial tumour cells and their stroma is very crucial in tumour progression and metastatic cascade. To escape from the primary tumour and invade adjacent tissues, cancer cells must interact with the extracellular matrix at several stages [5]. Invasive cancer cells are believed to breach the basal membrane using specialised protrusions called invadopodia [6-8]. The forces that drive tumour cell migration and 
invasion are provided by the actin cytoskeleton underlying the membrane protrusions $[9,10]$. Fascin is a $55 \mathrm{kDa}$ actin-bundling protein and is an important regulatory element in the maintenance and stability of parallel bundles of filamentous actin in a variety of cellular contexts. The ability of fascin to bind and bundle actin plays a central role in the regulation of cell adhesion, migration, and invasion [11].

CD44 is a transmembrane receptor protein that belongs to the family of adhesion molecules and is expressed on the surface of diverse cell types [12]. This glycoprotein has a critical role in extracellular matrix adhesion and is implicated in a series of cellular events, such as lymphocyte homing, leukocyte activation, lymphopoiesis, embryogenesis, and wound healing [13]. CD44 is encoded by a single gene containing 20 exons, 10 of which (v1-v10) are variant exons [14]. The overexpression of the variant form, CD44v6, which contains sequences encoded by exon 6 , has been proposed as a potential prognostic marker in many epithelial and nonepithelial malignancies in both early and metastatic phases of carcinogenesis [13].

Fascin expression has been evaluated in several human neoplasia, and recently in epithelial tumours [15-30], but to our knowledge only two studies have been conducted on the significance of fascin expression in endometrioid carcinomas [31,32]. With regard to CD44 and its variants, several studies have investigated its expressions in endometrial pathologies, including adenocarcinomas, yielding different results [31-41]. Our purpose was to evaluate the possible roles of these two molecular markers, fascin and CD44, in the invasive and metastatic behavior of endometrioid carcinoma and to analyse their association with clinicopathological features.

\section{Methods}

\section{Patients}

We studied 47 well-documented cases of endometrioid adenocarcinoma for which archival material of surgical specimens from primary tumour resections were available between 2006 and 2011 at the Pathology Department of Bulent Ecevit University Hospital. Tumours were staged according to the 2010 FIGO (The International Federation of Gynecology and Obstetrics) staging system. The hematoxylin and eosin stained sections were reviewed to determine the FIGO grade, the depth of myometrial invasion (if present), and the presence or absence of lymphovascular invasion and neural invasion. The macroscopic sizes and the FIGO stage of all tumours were also noted. Proliferative phase endometrium tissue samples were obtained from 10 cases.

\section{Immunohistochemical staining}

The sections $(4-5 \mu \mathrm{m})$ obtained from representative tissue sample blocks were deparaffinised with xylene, rehydrated in graded alcohols, and placed in $0.5 \%$ hydrogen peroxide in methanol for $10 \mathrm{~min}$ to block endogeneous peroxidase activity. Antigen retrieval was carried out by incubation in $0.01 \mathrm{M}$ citrate buffer (ph 6.0) for $5 \mathrm{~min}$ in a pressure cooker. The sections were exposed to the primary antibody for $60 \mathrm{~min}$ at room temperature. The standard streptavidin-biotin-peroxidase complex method was used for fascin (IM20, Novocastra, Newcastle, UK, 1:400) and CD44v6 (VVF-7, Novocastra, Newcastle, UK, $1: 50$ ) by employing diaminobenzidine (DAB) as the chromogen. Human tonsil was used as a positive control, while negative controls were obtained by omitting the primary antibody.

\section{Evaluation of immunohistochemical staining}

We calculated the "immunohistochemical score" (IHS) of fascin and CD44v6 for each case. The scoring system used for both fascin and CD44v6 was similar to previously published methods $[20,40]$. The extent of positively stained epithelial cells was estimated and classified on a four-point scale as follows: no staining $=0 \%, 1=1 \%-$ $10 \%, 2=11 \%-25 \%, 3=26 \%-50 \%$, and $4=51 \%-100 \%$. The intensity of the immunoexpression was categorised into three groups: weak $(+1)$, moderate $(+2)$, and strong $(+3)$. A final IHS score was obtained by multiplying the score for extent and the score for intensity. Therefore, the combined immunoreactivity score ranged from 0 to 12. According to this, cases were categorised into three groups: 0 (absent), IHS $\leq 10$, and $\mathrm{IHS} \geq 11$.

\section{Statistical analysis}

Statistical analysis was conducted with SPSS 18.0 software (SPSS, Inc., Chicago, IL). Continuous variables were expressed as mean \pm standard deviation, and categorical variables were expressed as frequency and percentage. Pearson's chi-square test was used to determine the difference between groups. A $p$ value of less than 0.05 was considered statistically significant for all tests.

\section{Results}

Immunohistochemical expression of fascin

The median age of the patients was $58.60(\mathrm{SD} \pm 11.16)$ years, with a range of 34-79 years. The macroscopic tumour sizes varied from 1 to 9 , with a mean size of $4.41 \mathrm{~cm}(\mathrm{SD} \pm 11.16)$. According to the FIGO staging system, 19 tumours were in stage $1 \mathrm{~A}, 11$ in stage $1 \mathrm{~B}, 11$ in stage 2, 3 in stage 3, and 4 in stage 4 . Histopathologically, there were 16 grade 1,16 grade 2 , and 15 grade 3 tumours. 
Fascin was detected in $72.34 \%$ (34 out of 47 ) of the cases in the tumour cell cytoplasm. Also, microvessel endothelium was stained with fascin in all carcinoma cases. In the tumour stroma only a few inflammatory cells including histiocytes showed weak fascin immunoreactivity. Epithelial staining was heterogeneous; while a score $\leq 10$ was detected in $56.25 \%$ (27) of the cases, a score $\geq 11$ was only seen in $16.66 \%$ (7) of the cases. The positively stained epithelial cells with fascin revealed various staining patterns, such as diffuse expression in a gland, patchy staining in a gland, or aggregation at the peripheral portion of a gland [Figures (a)-1(c)]. There was no obvious micro-anatomical distribution of fascin expression in terms of superficial portion and conventional invasive areas. In our series, only one case (grade 2) exhibited a microcystic, elongated, and fragmented (MELF)-type invasion pattern and fascin was expressed strongly in the neoplastic epithelium within these areas [Figure 1(d)]. The foci of squamous/morular differentiation were all strongly stained with fascin [Figure 1(e)].

In the proliferative endometrium, the stroma stained diffusely and homogeneously in all samples. However, glandular epithelium stained weakly in three $(30 \%)$ of the samples [Figure 1(f)]. A statistically significant difference with fascin expression was found between

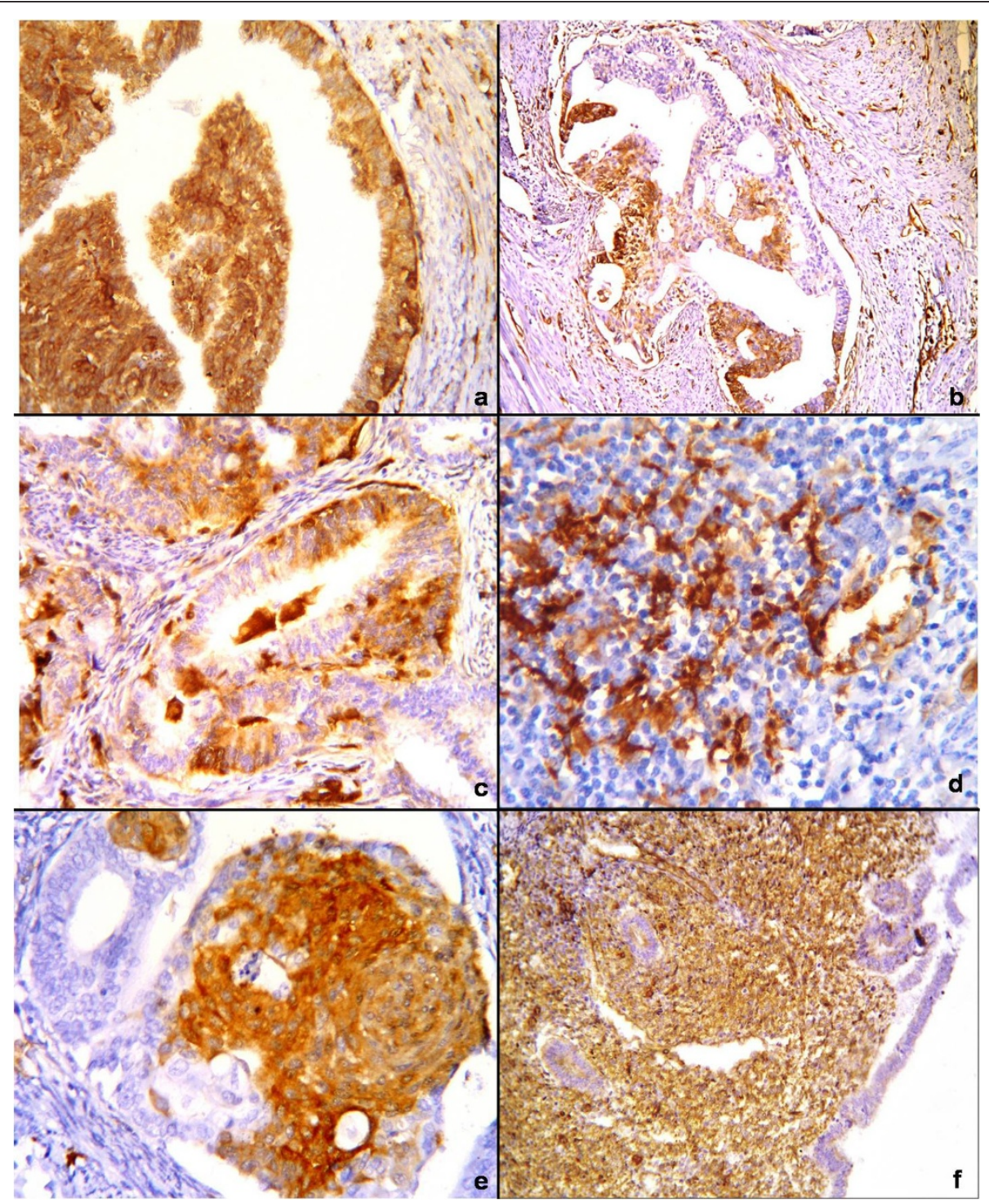

Figure 1 Immunohistochemical staining for fascin. (a) Strong fascin expression in tumour glands. (b) Heterogeneous expression was seen in the same gland. (c) Areas where immunoreactivity was seen at the peripheral portion of the glands. (d) The expression in an MELF-type area in a grade 2 tumour. (e) The expression in the areas of squamous differentation. (f) Diffuse staining of stroma in proliferative endometrium. B-SA peroxidase, DAB: $[(\mathbf{a})$ and $(\mathbf{c})] \times 200$, $[(\mathbf{b}),(\mathbf{e})$, and $(\mathbf{f})] \times 100$, and $(\mathbf{d}) \times 400$. 
Table 1 Comparison of cases with endometrioid carcinoma and proliferative endometrium

\begin{tabular}{|c|c|c|c|c|}
\hline & $\begin{array}{l}\text { IHS } \\
\text { score }\end{array}$ & $\begin{array}{c}\text { Endometrioid } \\
\text { carcinoma } \\
(n=47)\end{array}$ & $\begin{array}{l}\text { Proliferative } \\
\text { endometrium } \\
\quad(n=10)\end{array}$ & $P$ value \\
\hline \multirow[t]{3}{*}{ Fascin } & 0 & $13(27.7 \%)$ & 7 (70.0\%) & $p=0.023$ \\
\hline & $\leq 10$ & $27(57.4 \%)$ & $3(30.0 \%)$ & \\
\hline & $\geq 11$ & $7(14.2 \%)$ & $0(0 \%)$ & \\
\hline \multirow[t]{3}{*}{ CD44v6 } & 0 & 25 (53.2\%) & $6(60.0 \%)$ & $p=0.542$ \\
\hline & $\leq 10$ & $19(40.4 \%)$ & $4(40 \%)$ & \\
\hline & $\geq 11$ & $3(6.4 \%)$ & $0(0 \%)$ & \\
\hline
\end{tabular}

IHS: immunohistochemical score.

endometrioid carcinoma cases and proliferative endometrial samples $(p=0.023)$ (Table 1$)$.

Fascin expression was found to be significantly correlated with tumour grade $(p=0.003)$ and with neural invasion $(p=0.036)$ (Table 2$)$. This finding was only seen on a univariate analysis. As these variables were highly correlated (multicollinearity), binary logistic regression analysis did not fit the model and couldn't be done. However, no correlation was detected between fascin expression and tumour size, degree of myometrial invasion, lymphovascular invasion, and tumour stage $(p>0.05)$.

\section{Immunohistochemical expression of CD44v6}

The neoplastic glands in $46.80 \%$ (22 out of 47 ) of the cases showed cytoplasmic and membranous CD44v6 reactivity. The CD44v6 staining pattern was observed as cytoplasmic and/or membranous in tumour cells [Figure 2(a) and 2(b)], but cytoplasmic expression was the predominant pattern. In squamous/morular differentiation areas, however, membranous expression was strong and widespread [Fig. 2(c)]. The staining was not diffuse, and the total IHS score was calculated as $\geq 11$ in only three tumours. No CD44v6 expression was seen within the MELF-type neoplastic epithelium, and no special micro-anatomical distribution was observed. Also stromal tumour cells were not stained with CD44v6. In four (40\%) of the proliferative endometrial samples, CD44v6 expression was weak only in the glandular epithelium [Fig. 2(d)]. Statistically, no difference was found between endometrioid carcinoma cases and proliferative endometrial samples $(p=0.542)$.

Table 2 Correlation of clinicopathological parameters with fascin and CD44v6 expressions in 47 endometrioid carcinoma

\begin{tabular}{|c|c|c|c|c|c|c|c|c|}
\hline \multirow[t]{2}{*}{ Variables } & \multicolumn{4}{|c|}{ Fascin } & \multicolumn{4}{|c|}{ CD44v6 } \\
\hline & $\begin{array}{c}\text { Absent } \\
n=13(\%)\end{array}$ & $\begin{array}{c}\mathrm{IHS} \leq 10 \\
\mathrm{n}=27(\%)\end{array}$ & $\begin{array}{l}\text { IHS } \geq 11 \\
n=7(\%)\end{array}$ & $P$ value & $\begin{array}{c}\text { Absent } \\
n=25(\%)\end{array}$ & $\begin{array}{c}\mathrm{IHS} \leq 10 \\
\mathrm{n}=19(\%)\end{array}$ & $\begin{array}{l}\text { IHS } \geq 11 \\
n=3(\%)\end{array}$ & $P$ value \\
\hline \multicolumn{9}{|l|}{ Mass size } \\
\hline$\leq 4$ & $7(53.8 \%)$ & $13(48.1 \%)$ & $3(42.9 \%)$ & 0.889 & $12(48.0 \%)$ & $9(47.4 \%)$ & $2(66.7 \%)$ & 0.814 \\
\hline$\geq 5$ & $6(46.2 \%)$ & $14(51.9 \%)$ & $4(57.1 \%)$ & & $13(52.0 \%)$ & $10(52.6 \%)$ & 1 (33.3\%) & \\
\hline \multicolumn{9}{|l|}{ Grade } \\
\hline G1 & $9(69.2 \%)$ & 7.(25.9\%) & $0(0 \%)$ & 0.003 & $11(44.0 \%)$ & $5(26.3 \%)$ & $0(0 \%)$ & 0.322 \\
\hline $\mathrm{G} 2$ & $3(23.1 \%)$ & $11(40.7 \%)$ & 2.(28.6\%) & & 7 (28.0\%) & $8(42.1 \%)$ & 1.(33.3\%) & \\
\hline G3 & $1(7.7 \%)$ & $9(33.3 \%)$ & $5(71.4 \%)$ & & $7(28.0 \%)$ & $6(31.6 \%)$ & $2(27.7 \%)$ & \\
\hline \multicolumn{9}{|l|}{ Depth of MI } \\
\hline Absent & $2(15.4 \%)$ & $0(0 \%)$ & $0(0 \%)$ & 0.244 & $2(8.0 \%)$ & $0(0 \%)$ & $0(0 \%)$ & 0.527 \\
\hline Superficial & $5(38.5 \%)$ & $13(48.1 \%)$ & $3(42.9 \%)$ & & $10(40.0 \%)$ & $9(47.4 \%)$ & $2(66.7 \%)$ & \\
\hline Deep & $6(46.2 \%)$ & $14(51.9 \%)$ & $4(57.1 \%)$ & & $13(52.0 \%)$ & $10(52.6 \%)$ & 1 (33.3\%) & \\
\hline \multicolumn{9}{|l|}{ LVI } \\
\hline Absent & $9(69.2 \%)$ & 17 (63.0\%) & $2(28.6 \%)$ & 0.182 & $13(52.0 \%)$ & $12(63.2 \%)$ & $3(100.0 \%)$ & 0.150 \\
\hline Present & $4(30.8 \%)$ & 10 (37.0\%) & $5(71.4 \%)$ & & $12(48.0 \%)$ & $7(36.8 \%)$ & $0(0 \%)$ & \\
\hline \multicolumn{9}{|l|}{$\mathrm{NI}$} \\
\hline Absent & $11(84.6 \%)$ & $26(96.3 \%)$ & $4(57.1 \%)$ & 0.036 & 22 (88.0\%) & 16 (84.2\%) & $3(100.0 \%)$ & 0.613 \\
\hline Present & $2(15.4 \%)$ & $1(3.7 \%)$ & $3(42.9 \%)$ & & $3(12.0 \%)$ & $3(15.8 \%)$ & $0(0 \%)$ & \\
\hline \multicolumn{9}{|l|}{ Stage } \\
\hline 1 & $8(61.5 \%)$ & $18(66.7 \%)$ & $3(42.9 \%)$ & 0.597 & 17 (68.0\%) & $10(52.6 \%)$ & $2(66.7 \%)$ & 0.084 \\
\hline 2 & $3(23.1 \%)$ & $6(22.2 \%)$ & $2(28.6 \%)$ & & $3(12.0 \%)$ & $8(42.1 \%)$ & $0(0 \%)$ & \\
\hline 3 & $1(7.7 \%)$ & $2(7.4 \%)$ & $0(0 \%)$ & & $2(8.0 \%)$ & $0(0 \%)$ & 1 (33.3\%) & \\
\hline 4 & $1(7.7 \%)$ & $1(3.7 \%)$ & $2(28.6 \%)$ & & $3(12.0 \%)$ & $1(5.3 \%)$ & $0(0 \%)$ & \\
\hline
\end{tabular}

IHS: immunohistochemical score, MI: myometrial invasion, LVI: lymphovascular invasion, NI: neural invasion. 


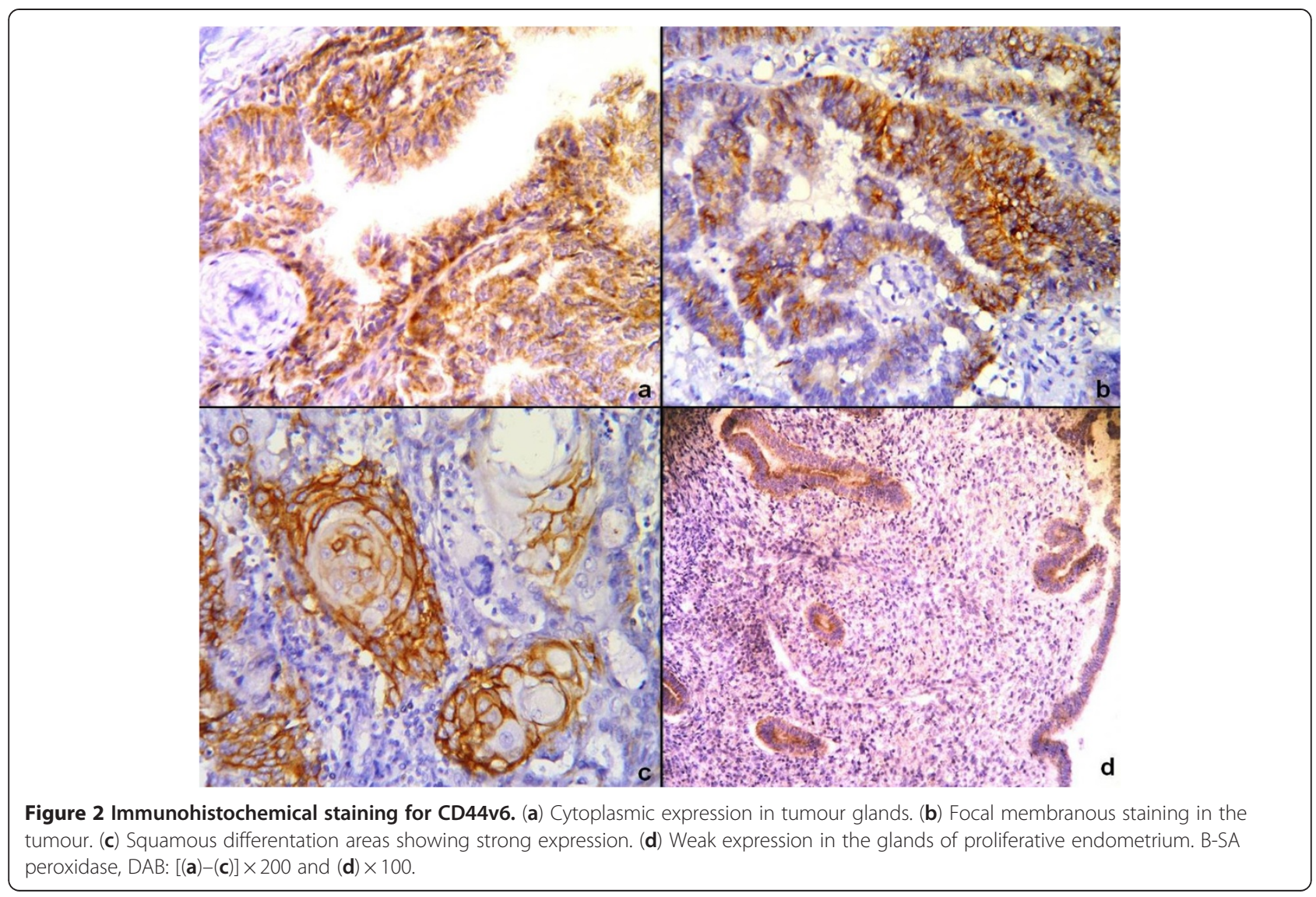

Additionally, no significant correlation was detected between the expression of CD44v6 and any clinicopathological features of endometrioid carcinoma cases, such as tumour size, tumour grade, depth of myometrial invasion, lymphovascular invasion, neural invasion, and stage $(p>0.05)$.

\section{Discussion}

Fascin and CD44 are proteins involved in different steps in the extracellular matrix invasion. The interaction between epithelial and stromal cells is important in tumour progression and metastasis; cancer cells use invasive fingerlike protrusions called invadopodia to invade the basal membrane and to degrade the extracellular matrix [6]. These protrusions carry actin bundles under the membrane $[6,9,10]$. At that point, fascin, the so-called actin-bundling protein, becomes a part of this process and is essential for the stability of actin microfilaments. It also facilitates the invasion [9].

Experimental studies demonstrated that CD44 was strongly associated with the actin cytoskeleton in an indirect position, and this interaction is mediated by ERM (ezrin-radixin-moesin) proteins [14,42,43]. ERM adapts CD44 to the actin-based cytoskeleton and organises the membrane and cytoskeleton interaction. However, little knowledge is known about the relationship between fascin and CD44 in solid tumours. In the present study, we examined fascin along with CD44v6 in 47 endometrioid carcinoma and 10 proliferative endometrium samples. We demonstrated that the expression of these two molecular proteins did not correlate with each other.

Fascin has recently received considerable attention as a new prognostic marker in several solid neoplasms. In the present study, we detected fascin in $72.34 \%$ of endometrioid carcinoma, and the expression was significantly different from the normal group. Among the studies about fascin in endometrial carcinomas, Kabukcuoglu et al. revealed positive staining in $74 \%$ of the carcinoma specimens and in $39 \%$ of the non-neoplastic endometrial samples [31]. They also indicated that higher-grade endometrial carcinoma cases revealed a significant increase in the total epithelial fascin expression. These results are considerably compatible with our findings that fascin was significantly correlated with histological grade. Stewart et al. also demonstrated strong fascin immunoreactivity in the neoplastic epithelium of MELF-type invasion areas in contrast to negative or weakly stained conventional tumour glands in low-grade uterine endometrioid adenocarcinoma. In addition, prominent staining within the peripheral epithelial cell and in the foci of squamous/morular-type differentiation was observed [32]. 
Of the 47 cases, only one (a grade 2 tumour) showed an MELF-type invasion pattern and revealed strong fascin expression. In a unique study determining the exact nature of the MELF pattern of invasion, the immunprofile in MELF areas was found to be consistent with the features of epithelial-mesenchymal transition [44].

Although areas of squamous or morular differentiation are frequently observed in endometrioid carcinomas, their pathogenesis remain unclear. In studies that investigated the precise nature of squamous differentiation in endometrial carcinoma, these areas were found to express beta catenin [45-47]. In our series, areas with squamous and morular differentation expressed both fascin and CD44v6 strongly. CD44v6 expression can be detected in a subset of squamous cell carcinoma in different locations and in the foci of squamous differentation $[41,48,49]$. This finding was attributed to the fact that the cells were packed tightly in these foci, as seen in squamous cell carcinoma of any organ or in solid nests within an otherwise adenocarcinoma [49]. Meanwhile the presence of fascin expression in squamous and morular differentiation was explained by the activation of the Wnt signalling pathway and the upregulation of fascin via nuclear translocation of beta catenin [32].

The immunoexpression of fascin and CD44v6 was predominantly heterogeneous, while diffuse and strong expressions were seen in $6.4 \%$ and $14.2 \%$ of cases, respectively. Fascin immunostaining was sometimes restricted to the periphery of the neoplastic glands. However, no special staining distribution was seen between the glands in the superficial portion of the tumour and in the deep invasive conventional areas. Being a dynamic process, carcinogenesis might be responsible for the heterogeneity of protein expressions.

CD44v6 has been implicated in the malignant transformation and metastatic potential of several tumours and in endometrial carcinomas. Among the previous analyses of CD44 in endometrial adenocarcinoma, some investigators found no relation between CD44v6 and clinicopathological parameters and thought that CD44v6 was not an adverse predictive factor [33-35]. However, the others indicated that CD44v6 was inversely correlated with adverse prognostic factors $[37,38]$. In this study, CD44v6 was demonstrated in $46.80 \%$ of carcinoma specimens and in $40 \%$ of the proliferative phase. Meanwhile, no correlation was found between any of the clinicopathological features. The expression of CD44v6 may be seen as a result of disregulation and is not primarly implicated in the progression of endometrial cancer.

\section{Conclusions}

Our findings suggest that fascin may become a novel marker in the prognosis of endometrial cancer. However, further detailed studies in a larger series that should include prospective clinicopathological analyses and menstrual cycle phases are neccessary to determine the significance of these molecules in physiological conditions and in endometrial tumors as a prognostic indicator or a molecular target for treatment.

\section{Abbreviations}

IHS: Immunohistochemical score; MELF: Microcystic, elongated, and fragmented; FIGO: The International Federation of Gynecology and Obstetrics.

\section{Competing interests}

The authors declare that they have no competing interests.

\section{Acknowledgement}

We would like to sincerely thank Firuzan Kokturk for her assistance in the statistical analyses.

\section{Authors' contributions}

BDG conducted the study design, performed microscopic evaluation, and drafted the manuscript. BB participated in the design of the study and helped to draft the manuscript. SB participated in the design of the study and performed microscopic evaluation. FB, GY, and NOK participated in the microscopic and immunohistochemical evaluation. SOO participated in the study design and coordination. All authors read and approved the final manuscript.

Received: 27 April 2012 Accepted: 11 July 2012

Published: 11 July 2012

\section{References}

1. Hedrick Ellenson L, Ronnett BM, Soslow RA, Zaino RJ, Kurman RJ: Endometrial carcinoma. In Blaustein's Pathology of the Female Genital Tract. 6th edition. Edited by Kurman RJ, Hedrick Ellenson L, Ronnett BM. New York: Springer; 2010:393-452.

2. Stewart CJ, Crook ML, Leung YC, Platten M: Expression of cell cycle regulatory proteins in endometrial adenocarcinoma: variations in conventional tumor areas and in microcystic, elongated and fragmented glands. Mod Pathol 2009, 22:725-733.

3. Köbel M, Langhammer T, Hüttelmaier S, Schmitt WD, Kriese K, Dittmer J, Strauss HG, Thomssen C, Hauptmann S: Ezrin expression is related to poor prognosis in FIGO stage I endometrioid carcinomas. Mod Pathol 2006, 19:581-587.

4. Salvesen $\mathrm{HB}$, Akslen LA: Molecular pathogenesis and prognostic factors in endometrial carcinoma. APMIS 2002, 110:673-689.

5. Kumar V, Abbas AK, Fausto N: Neoplasia. In Robbins and Cotran Pathologic Basis Of Disease. 7th edition. Edited by Kumar V, Abbas AK, Fausto N. Philadelphia: Elsevier Saunders; 2005:269-342.

6. Schoumacher M, Goldman RD, Louvard D, Vignjevic DM: Actin, microtubules, and vimentin intermediate filaments cooperate for elongation of invadopodia. J Cell Biol 2010, 189:541-556.

7. Machesky LM, Li A: Fascin: Invasive filopodia promoting metastasis. Commun Integr Biol 2010, 3:263-270.

8. Arjonen A, Kaukonen R, Ivaska J: Filopodia and adhesion in cancer cell motility. Cell Adh Migr 2011, 5:421-430.

9. Li A, Dawson JC, Forero-Vargas M, Spence HJ, Yu X, König I, Anderson K, Machesky LM: The actin-bundling protein fascin stabilizes actin in invadopodia and potentiates protrusive invasion. Curr Biol 2010, 20:339-345.

10. Köhler S, Schaller V, Bausch AR: Collective dynamics of active cytoskeletal networks. PLOS One 2011, 6:e23798

11. Hashimoto Y, Kim DJ, Adams JC: The roles of fascins in health and disease. J Pathol 2011, 224:289-300

12. Goodison S, Urquidi V, Tarin D. CD44 cell adhesion molecules. Mol Pathol 1999, 52:189-196.

13. Sneath RJ, Mangham DC: The normal structure and function of CD44 and its role in neoplasia. Mol Pathol 1998, 51:191-200.

14. Rudzki Z, Jothy S: CD44 and the adhesion of neoplastic cells. Mol Pathol 1997, 50:57-71. 
15. Wu HH, Zafar S, Huan $Y$, Yee H, Chiriboga L, Wang BY: Fascin over expression is associated with dysplastic changes in sinonasal inverted papillomas: a study of 47 cases. Head Neck Pathol 2009, 3:212-216.

16. Ortiz CM, Ito T, Hashimoto $Y$, Nagayama S, Iwai A, Tsunoda S, Sato F, Martorell M, Garcia JA, Perez A, Shimada Y: Effects of small interfering RNAs targeting fascin on human esophageal squamous cell carcinoma cell lines. Diagn Pathol 2010, 5:41.

17. Takikita M, Hu N, Shou JZ, Giffen C, Wang QH, Wang C, Hewitt SM, Taylor PR: Fascin and CK4 as biomarkers for esophageal squamous cell carcinoma. Anticancer Res 2011, 31:945-952.

18. Hashimoto Y, Shimada Y, Kawamura J, Yamasaki S, Imamura M: The prognostic relevance of fascin expression in human gastric carcinoma. Oncology 2004, 67:262-270.

19. Hashimoto $Y$, Skacel M, Lavery IC, Mukherjee AL, Casey G, Adams JC: Prognostic significance of fascin expression in advanced colorectal cancer: an immunohistochemical study of colorectal adenomas and adenocarcinomas. BMC Cancer 2006, 6:241.

20. Ozerhan $1 \mathrm{H}$, Ersoz N, Onguru O, Ozturk M, Kurt B, Cetiner S: Fascin expression in colorectal carcinomas. Clinics (Sao Paulo) 2010, 65:157-164.

21. Jung EJ, Lee JH, Min BW, Kim YS, Choi JS: Clinicopathologic significance of fascin, extracellular matrix metalloproteinase inducer, and ezrin expressions in colorectal adenocarcinoma. Indian J Pathol Microbiol 2011 54:32-36.

22. Ozcan A, Karslioğlu Y, Günal A, Cermık AH, Kurt B, Ongürü O: Fascin expression and its potential significance in gastrointestinal stromal tumors. Turk J Gastroenterol 2011, 22:363-368.

23. Xu YF, YU SN, LU ZH, Liu JP, Chen J: Fascin promotes the motility and invasiveness of pancreatic cancer cells. World J Gastroenterol 2011 17:4470-4478.

24. Iguchi T, Aishima S, Umeda K, Sanefuji K, Fujita N, Sugimachi K, Gion T, Taketomi A, Maehara Y, Tsuneyoshi M: Fascin expression in progression and prognosis of hepatocellular carcinoma. J Surg Oncol 2009, 100:575-579.

25. Karasavvidou F, Barbanis S, Pappa D, Moutzouris G, Tzortzis V, Melekos MD, Koukoulis G: Fascin determination in urothelial carcinomas of the urinary bladder: a marker of invasiveness. Arch Pathol Lab Med 2008, 132:1912-1915.

26. Darnel AD, Behmoaram E, Vollmer RT, Corcos J, Bijian K, Sircar K, Su J, Jiao J, Alaoui-Jamali MA, Bismar TA: Fascin regulates prostate cancer cell invasion and is associated with metastasis and biochemical failure in prostate cancer. Clin Cancer Res 2009, 15:1376-1383.

27. Xing P, Li JG, Jin F, Zhao TT, Liu Q, Dong HT, Wei XL: Fascin, an actin-bundling protein, promotes breast cancer progression in vitro. Cell Biochem Funct 2011, 29:303-310.

28. Wen $\mathrm{YH}$, Yee $\mathrm{H}$, Goswami S, Shukla PS: Fascin expression in serous tumors of ovary correlates with aggressiveness of malignancy. Int J Gynecol Pathol 2009, 28:187-192.

29. Valkov A, Sorbye SW, Kilvaer TK, Donnem T, Smeland E, Bremnes RM, Busund LT: The prognostic impact of TGF- $\beta 1$, fascin, NF-KB and PKC- $\zeta$ expression in soft tissue sarcomas. PLoS One 2011, 6:e17507.

30. Sun J, He H, Xiong Y, Lu S, Shen J, Cheng A, Chang WC, Hou MF, Lancaster JM, Kim M, Yang S: Fascin protein is critical for transforming growth factor $\beta$ protein-induced invasion and filopodia formation in spindle-shaped tumor cells. J Biol Chem 2011, 286:38865-38875.

31. Kabukcuoglu S, Oner U, Ozalp SS, Dundar E, Yalcin OT, Colak E: Prognostic significance of fascin expression in endometrioid carcinoma. Eur $J$ Gynaecol Oncol 2006, 27:481-486.

32. Stewart CJ, Crook ML, Manso L: Fascin expression in low-grade uterine endometrioid adenocarcinoma: correlation with microcystic, elongated and fragmented (MELF)-type alteration at the deep invasive margin. Histopathology 2011, 59:73-80.

33. Katsura M, Furumoto $\mathrm{H}$, Nishimura M, Kamada M, Aono T: Overexpression of CD44 variants 6 and 7 in human endometrial cancer. Gynecol Oncol 1998, 71:185-189.

34. Tokumo K, Kodama J, Seki N, Miyagi Y, Yoshinouchi M, Kudo T: CD44 exon v6 is not implicated in the progression and metastasis of endometrial cancer. Cancer Lett 1998, 125:221-225.

35. Tempfer C, Haeusler G, Kaider A, Hefler L, Hanzal E, Reinthaller A, Breitenecker $G$, Kainz C: The prognostic value of CD44 isoform expression in endometrial cancer. Br J Cancer 1998, 77:1137-1139.
36. Leblanc M, Poncelet $C$, Soriano D, Walker-Combrouze F, Madelenat $P$, Scoazec JY, Darai E: Alteration of CD44 and cadherins expression: possible association with augmented aggressiveness and invasiveness of endometrial carcinoma. Virchows Arch 2001, 438:78-85.

37. Ayhan A, Tok EC, Bildirici I, Ayhan A: Overexpression of CD44 variant 6 in human endometrial cancer and its prognostic significance. Gynecol Oncol 2001, 80:355-358.

38. Stokes GN, Shelton JB Jr, Zahn CM, Kendall BS: Association of CD44 isoform immunohistochemical expression with myometrial and vascular invasion in endometrioid endometrial carcinoma. Gynecol Oncol 2002, 84:58-561

39. Afify AM, Craig S, Paulino AF, Stern R: Expression of hyaluronic acid and its receptors, CD44s and CD44v6, in normal, hyperplastic, and neoplastic endometrium. Ann Diagn Pathol 2005, 9:312-318.

40. Hong SC, Song JY, Lee JK, Lee NW, Kim SH, Yeom BW, Lee KW: Significance of CD44v6 expression in gynecologic malignancies. J Obstet Gynaecol Res 2006, 32:379-386.

41. Saegusa M, Hashimura M, Okayasu I: CD44 expression in normal, hyperplastic, and malignant endometrium. J Pathol 1998, 184:297-306.

42. Thorne RF, Legg JW, Isacke CM: The role of the CD44 transmembrane and cytoplasmic domains in co-ordinating adhesive and signalling events. J Cell Sci 2004, 117:373-380.

43. Tsukita S, Oishi K, Sato N, Sagara J, Kawai A, Tsukita S: ERM family members as molecular linkers between the cell surface glycoprotein CD44 and actin-based cytoskeletons. J Cell Biol 1994, 126:391-401.

44. Stewart CJ, Brennan BA, Leung YC, Little L: MELF pattern invasion in endometrial carcinoma: association with low grade, myoinvasive endometrioid tumours, focal mucinous differentiation and vascular invasion. Pathology 2009, 41:454-459.

45. Nicolae A, Preda O, Nogales FF: Endometrial metaplasias and reactive changes: a spectrum of altered differentiation. J Clin Pathol 2011, 64:97-106.

46. Saegusa M, Okayasu I: Frequent nuclear beta-catenin accumulation and associated mutations in endometrioid-type endometrial and ovarian carcinomas with squamous differentiation. J Pathol 2001, 194:59-67.

47. Ashihara K, Saito T, Mizumoto H, Adachi K, Tanaka R, Nishimura M, Ito E, Kudo R: Loss of gamma-Catenin expression in squamous differentiation in endometrial carcinomas. Int J Gynecol Pathol 2002, 21:246-254.

48. Mack B, Gires O: CD44s and CD44v6 expression in head and neck epithelia. PLoS One 2008, 3:e3360.

49. Ylagan LR, Scholes J, Demopoulos R: Cd44: a marker of squamous differentiation in adenosquamous neoplasms. Arch Pathol Lab Med 2000 124:212-215.

doi:10.1186/1746-1596-7-80

Cite this article as: Gun et al:: Clinicopathological significance of fascin and CD44v6 expression in endometrioid carcinoma. Diagnostic Pathology 2012 7:80

\section{Submit your next manuscript to BioMed Central and take full advantage of:}

- Convenient online submission

- Thorough peer review

- No space constraints or color figure charges

- Immediate publication on acceptance

- Inclusion in PubMed, CAS, Scopus and Google Scholar

- Research which is freely available for redistribution 